This article is licensed under the Creative Commons Attribution-NonCommercial-NoDerivatives 40 Intera-

\title{
Peptide-Conjugated Quantum Dots Act as the Target Marker for Human Pancreatic Carcinoma Cells
}

\author{
Shuang-ling Li Jing Yang Xiao-fei Lei Jian-na Zhang Hong-li Yang Kun Li \\ Chang-qing $\mathrm{Xu}$ \\ Department of gastroenterology, Shandong Provincial Qianfoshan Hospital, Shandong University, \\ Jinan, China
}

\section{Key Words}

Nanotechnology $•$ Quantum dots $•$ Cyclic RGD $・$ Targeted marking • Biocompatibility

\begin{abstract}
Background/Aims: In the present study, we describe a novel and straightforward approach to produce a cyclic- arginine-glycine-aspartic (RGD)-peptide-conjugated quantum dot (QD) probe as an ideal target tumor biomarker. Due to its specific structure, the probe can be used for targeted imaging of pancreatic carcinoma cells. Methods: Pancreatic carcinoma cells were routinely cultured and marked with QD-RGD probe. The QD-RGD probe on the fluorescencelabeled cancer cell was observed by fluorescence microscopy and laser confocal microscopy. Cancer cell viability was detected by MTT assay after culturing with QD-RGD probe. Results: Fluorescence microscopy and laser confocal microscopy displayed that $10 \mathrm{nmol} / \mathrm{L}$ QD-RGD probe was able to effectively mark pancreatic carcinoma cells. In comparison with organic dyes and fluorescent proteins, the quantum dot-RGD probe had unique optical and electronic properties. Conclusion: QD-RGD probe has a low cytotoxicity with an excellent optical property and biocompatibility. These findings support further evaluation of QD-RGD probes for the early detection of pancreatic cancer.

\section{Introduction}

Pancreatic cancer is an aggressive and deadly malignancy that is diagnosed in more than 40,000 patients annually in the United States, where it is the fourth leading cause of cancer-related deaths [1]. Most pancreatic cancers are not diagnosed until after the cancer 


\section{Cellular Physiology Cell Physiol Biochem 2016;38:1121-1128 and Biochemistry Published online: March 11, $2016 \quad$\begin{tabular}{l|l} 
DOI: 10.1159/000443062 & $\begin{array}{l}\text { (c) } 2016 \text { The Author(s). Published by S. Karger AG, Basel } \\
\text { www.karger.com/cpb }\end{array}$
\end{tabular} \\ Li et al.: Quantum Dots as Novel Marker for Pancreatic Cancer Cells}

has spread to other organs and is no longer curable, which reflects the ineffectiveness of current therapies and the profound direness of this disease. The overwhelming majority of patients present with locally advanced or metastatic malignancies, rendering the cancers surgically unresectable [2]. The use of palliative chemotherapy and radiation therapy has also been shown to be ineffective in ameliorating the prognosis of this uniformly lethal disease. Thus, in order to improve the survival rate of patients with pancreatic cancer, it is critical that ultrasensitive targeted bioimaging probes be developed that can specifically detect pancreatic cancer at its earliest stage [3], and hence potentially curative [4].

Semiconductor quantum dots (QDs) are tiny light-emitting particles on the nanometer scale that are now emerging as a new class of fluorescent label for biology and medicine. In comparison with traditional fluorescent probes, such as organic dyes and fluorescent proteins, QDs have significant advantages [5-8]. For example, they have robust photochemical stability, excellent resistance to chemical and photochemical degradation, and size-tunable photoluminescence that ranges from visible to near-IR with sharp spectral bands [9-11]. QDs also provide a versatile nanoscale scaffold for designing multifunctional nanoparticles with imaging and therapeutic functions, such as conjugation with antibodies, peptides, or small molecules [12]. Thus, QDs have recently attracted much attention as new generation probes for optical bioimaging [11-14]. The integrin $\alpha v \beta_{3}$ receptor, which binds to a number of extracellular matrix proteins, is not generally expressed in normal tissues, but is significantly upregulated on blood vessels undergoing angiogenesis. The overexpression of integrin $\alpha v \beta_{3}$ had been demonstrated in pancreatic cancer cells, and it plays an important role in tumor growth and metastasis $[15,16]$. The ability to target the integrin $\alpha v \beta_{3}$ receptor on cancer cells increases the efficacy of targeted therapy and reduces side effects. In this study, we used a novel, facile, and straightforward approach to generate a cyclic Arg-Gly-Asp (RGD)-peptide conjugated QD formulation as an ideal target tumor biomarker. We demonstrated the high affinity and specificity of this probe. In addition, the QD-RGD probe showed low cytotoxicity to the SW1990 human pancreatic cancer cell line. These findings support further evaluation of the QD-RGD probe for the early detection of pancreatic cancer.

\section{Materials and Methods}

\section{Materials}

The SW1990 human pancreatic cancer cell line was purchased from the Cell Bank of the Chinese Academy of Sciences. Cyclic RGD peptides were purchased from GL Biochem. Type II CdTe/CdS QDs were provided by Professor J. C. Zhang (School of Materials Science and Engineering, Shanghai University). Dulbecco's minimum essential media (DMEM), fetal bovine serum (FBS), penicillin, streptomycin, and $0.25 \%$ parenzyme were purchased from Gibco. DAPI and MTT were purchased from Aldrich. All chemicals (mercaptosuccinic acid [MSA], EDC, NHS, and DMSO) were used as received.

Preparation and Purification of the QD-RGD Probe

We mixed the QD solution with MSA, and the molar ratio of Cd:Te:Se:MSA was 1:0.2:0.4:1.5. Next, we added NHS (0.02 mmol/L) and EDC $(0.01 \mathrm{mmol} / \mathrm{L})$ to the MSA-modified QD solution, adjusting the $\mathrm{pH}$ to 7.2 - 7.4 using a PBS solution. The solution was stored at $4^{\circ} \mathrm{C}$ until use. Each mixture was stirred gently for $20 \mathrm{~min}$.

One milliliter of this solution was mixed with $0.5 \mathrm{~mL}$ of $1.2 \mathrm{mg} / \mathrm{mL}$ cyclic RGD peptide solution (the molar ratio of maleimide to RGD peptide was 1:2) and stirred gently for $60 \mathrm{~min}$. Next, the resulting bioconjugate dispersion was purified further using centrifugation at 10,000 rpm for $15 \mathrm{~min}$. The QD precipitate was re-dispersed in $1 \mathrm{~mL} \mathrm{HPLC}$ water and kept at $4^{\circ} \mathrm{C}$ until use.

Characterization of the Crystal Structure of the QD-RGD Probe

High-resolution transmission electron microscopy (HRTEM) images of the prepared QD-RGD probe were obtained using a JEOL model JEM 2010 microscope at an acceleration voltage of $200 \mathrm{kV}$. 


\section{Cellular Physiology Cell Physiol Biochem 2016;38:1121-1128

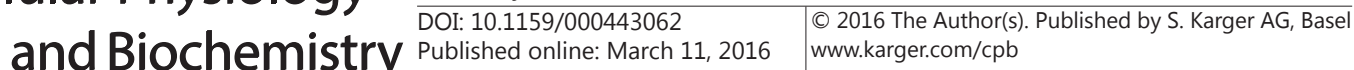 \\ Li et al.: Quantum Dots as Novel Marker for Pancreatic Cancer Cells}

\section{Cell Culture and Imaging}

SW1990 cells were cultured in DMEM supplemented with 10\% FBS, $100 \mathrm{IU} / \mathrm{mL}$ penicillin, and 100 $\mu \mathrm{g} / \mathrm{mL}$ streptomycin at $37^{\circ} \mathrm{C}$ under $5 \% \mathrm{CO}_{2}$, and plated at $2.0 \times 10^{5} \mathrm{cells} / \mathrm{cm}^{2}$ on non-coated 6-well plastic culture plates. The day before adding the QD-RGD probe, the cells were seeded at a confluence of $80 \%$. The QD-RGD probe was added to the plates at a final concentration of $10 \mathrm{nmol} / \mathrm{L}$ at $37^{\circ} \mathrm{C}$ for 12,24 , and $48 \mathrm{~h}$. After incubation, the cells were washed 3 times with PBS and imaged using a fluorescence microscope with UV excitation.

For further observation of the QD-RGD probe on the fluorescence-labeled cells, we used a laser scanning confocal microscope with laser excitation at $405 \mathrm{~nm}$.

\section{In Vitro Cytotoxicity Assay}

For each MTT (3-[4, 5-Dimethylthiazol-2-yl]-2, 5-diphenyltetrazolium bromide) assay, SW1990 cells were plated in 4 wells of a tissue culture dish ( 6 sets, each set contains 4 wells). Five sets were treated with different concentrations of the QD-RGD probe and one set was the control. The complete assay was performed 3 times and the results were averaged. Various concentrations of QDs, ranging from 10 to 70 $\mathrm{nmol} / \mathrm{L}$, were added to each well and subsequently incubated with the cells for 12,24 , and $48 \mathrm{~h}$ at $37^{\circ} \mathrm{C}$ under $5 \% \mathrm{CO}_{2}$. As described in the literature, the absorbance of formazan (produced by the cleavage of MTT by dehydrogenases in living cells) is directly proportional to the number of live cells. After different incubation periods, we added the MTT reagent $(5 \mathrm{mg} / \mathrm{mL})$ to each well. The colored formazan products were quantified photometrically at $490 \mathrm{~nm}$ in a multi-mode microplate reader (Bio-Rad Laboratories, USA.). Cell viability was calculated as the ratio of the absorbance of the sample well to that of the control well and expressed as a percentage.

\section{Results}

Characteristics of the QD-RGD Probe

The QD-RGD probe was prepared using the peptide condensing agents EDC and NHS. The surface of the QDs contains a carboxyl group that can make a condensation reaction to form an amide bond with the amine groups of the RGD peptides. The QDs are covalently grafted to the RGD peptides to form a stable structure.

Figure 1 shows the QD-RGD probe fluorescing under UV excitation. As can be seen from the figure, QD-RGD probes with a range of colors were prepared. As the shell thickness of the QD-RGD probe increases, the particle size of the QDs also increases. Due to their nanometer size, the fluorescence emitted under UV excitation gradually changes from blue to red, and has relatively ideal fluorescence intensity. QDs with different fluorescent wavelengths (different colors) have considerable value for biological applications.

HRTEM generates high resolution, high magnification microscopic images. It is an effective tool for the observation and analysis of the organization and structure of the QDRGD probe.

Figure 2 shows typical HRTEM images of QD nanocrystals. The images clearly illustrate the high monodispersity of the nanoparticles. The particle sizes were estimated to be in the

Fig. 1. Fluorescence image of QD-RGD probes of different $n$ a n o m e t e r sizes. QD-RGD probes with a range of colors under UV excitation.

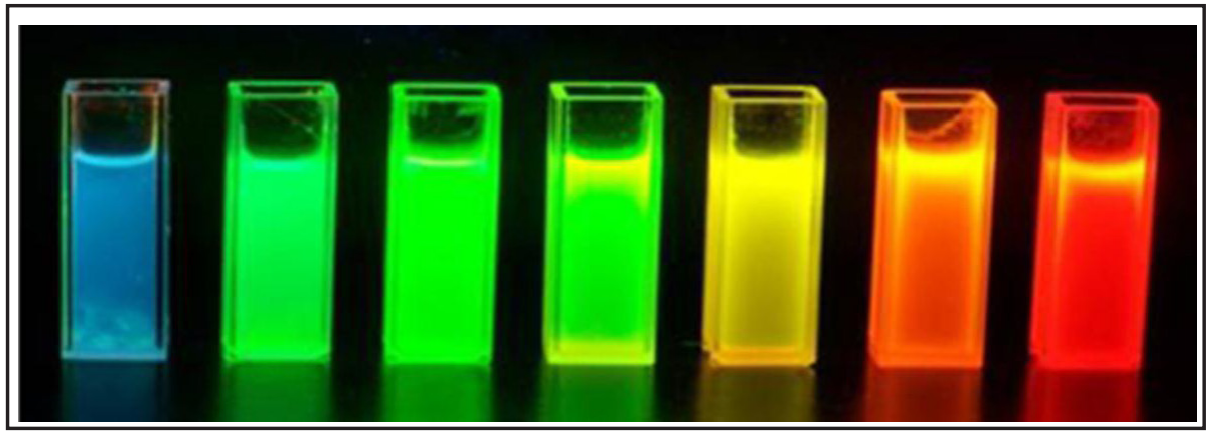




\section{Cellular Physiology Cell Physiol Biochem 2016;38:1121-1128 \begin{tabular}{l|l|l} 
DOI: 10.1159/000443062 & a 2016 The Author(s). Published by S. Karger AG, Basel \\
www.karger.com/cpb
\end{tabular}

Fig. 2. High-resolution transmission electron microscopy images of QD-RGD probes. The scale bar represents (A) $10 \mathrm{~nm}$ and (B) 5 nm, respectively. RGD means arginine-glycine-aspartic acid.
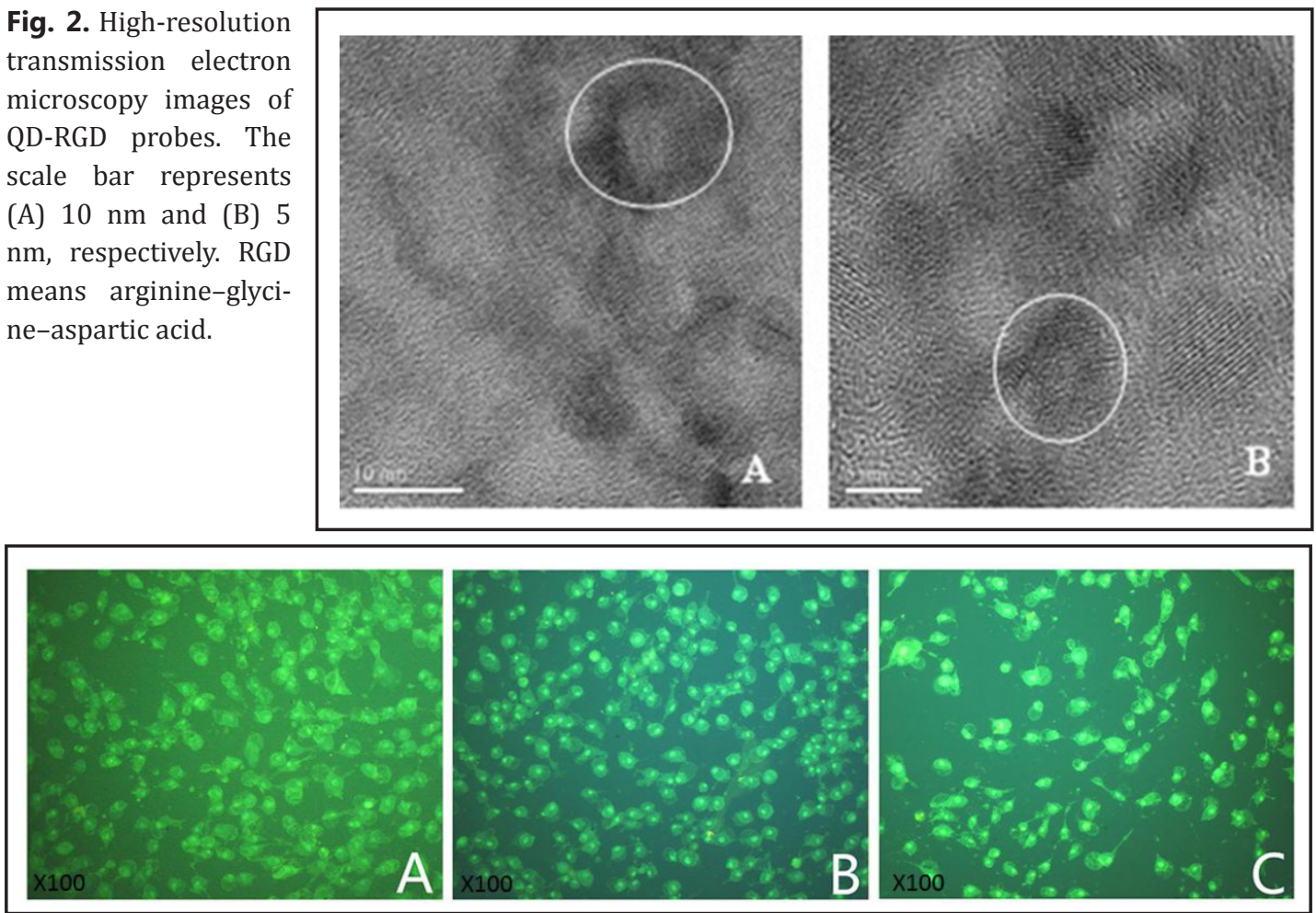

Fig. 3. Fluorescence images of SW1990 cells stained with the QD-RGD probe at different time points (original magnification, $\times 100$ ). $10 \mathrm{nmol} / \mathrm{L}$ of the QD-RGD probe were incubated with SW1990 cells for 12, 24, and $48 \mathrm{~h}$ at $37^{\circ} \mathrm{C}$. After incubation, the images were captured using a fluorescence microscope with UV excitation.

range of 3 - $4 \mathrm{~nm}$. Ultra-small QDs are favorable for targeted bio-imaging because their size can reduce their potential toxicity [17].

\section{In Vitro Imaging with the $Q D-R G D$ Probe}

The QD-RGD probe, which has retained its optical properties as shown above, was used to mark live pancreatic cancer cells. The QD-RGD probe fluoresced green under UV excitation fluorescence microscopy (Fig. 3). In addition, the QD-RGD probe marked SW1990 cells with high fluorescence intensity, which is ideal and valuable. The fluorescence quenching time of the QD-RGD probe was significantly longer than the ordinary organic dye; it can still fluoresce after 48 and $60 \mathrm{~h}$. Therefore, the QD-RGD probe has robust photochemical stability, excellent resistance to chemical and photochemical degradation, and can withstand repeated excitation.

Figure 4 shows confocal images of SW1990 cells marked with the QD-RGD probe. Figure $4 \mathrm{~A}$ shows a fluorescence image of the QD-RGD probe with laser excitation at $405 \mathrm{~nm}$. Figure 4B shows an SW1990 cell. Figure 4C shows DAPI staining of an SW1990 cell nucleus. Figure 4D shows an SW1990 cells marked with the QD-RGD probe. From this image, we can see clearly that the QD-RGD probe mainly marked the surface of the cell.

\section{In Vitro Cytotoxicity of the QD-RGD Probe}

The MTT experiment results showed that cytotoxicity was not significantly different ( $p$ $>0.05$ ) at 12 and $24 \mathrm{~h}$ between the experimental group treated with the QD-RGD probe (20 $\mathrm{nmol} / \mathrm{L})$ and the blank control group; however, there was a significant difference $(p<0.05)$ in cytotoxicity between the $40 \mathrm{nmol} / \mathrm{L}$ QD-RGD probe group and the blank control group. There was no significant difference $(p>0.05)$ in cytotoxicity between the QD-RGD $(15 \mathrm{nmol} / \mathrm{L})$ group and the blank control group; however, at $48 \mathrm{~h}$, there was a significant difference $(p<$ 


\section{Cellular Physiology and Biochemistry

Fig. 4. Confocal images of SW1990 cells marked with the QD-RGD probe. QD-RGD probe (10 nmol/L) was incubated with SW1990 cells. After incubation, the images were captured using a laser scanning confocal microscope. (A) The fluorescence image of the QD-RGD probe with laser excitation at $405 \mathrm{~nm}$. (B) A single SW1990 cell. (C) DAPI staining of an SW1990 cell nucleus. (D) SW1990 cells marked with the QD-RGD probe.

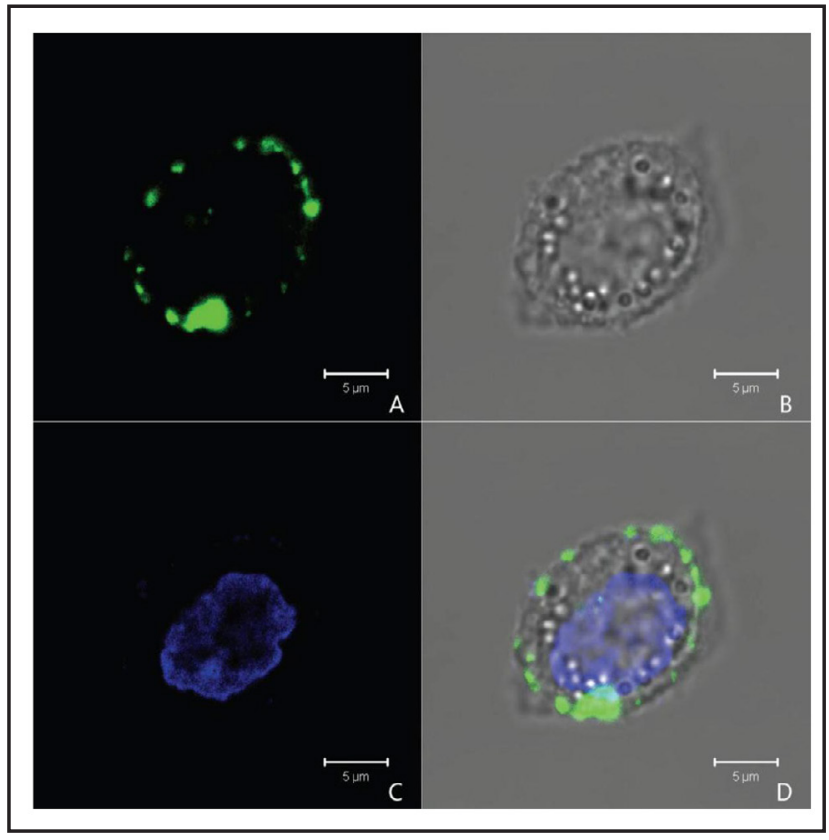

Fig. 5. Cell survival rate of cells exposed to different concentrations of QD-RGD for different time points. Various concentrations of QDs (10-70 nmol/L) were incubated with SW1990 cell for 12 , 24 , and $48 \mathrm{~h}$. The absorbance of the mixtures at $490 \mathrm{~nm}$ was measured.

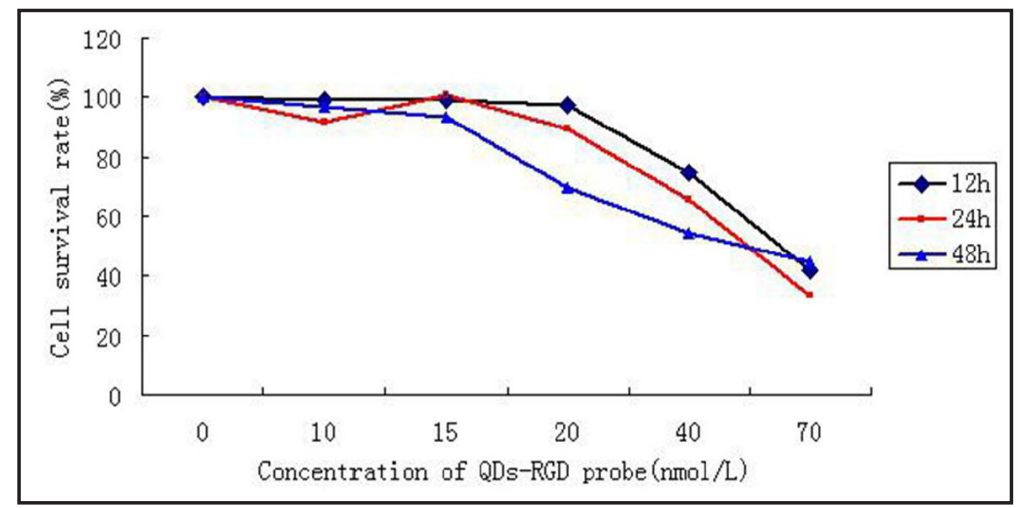

0.05 ) in cytotoxicity between the QD-RGD ( $\geq 20 \mathrm{nmol} / \mathrm{L}$ ) group and the blank control group. After adding different concentrations of the QD-RGD probe, the cells continued to grow. As the incubation time increased, the cell growth rate slowed down. Figure 5 shows the survival rate of SW1990 cells for different concentrations of the QD-RGD probe at different times. We observed that low concentrations ( $\leq 15 \mathrm{nmol} / \mathrm{L}$ ) of the QD-RGD probe had relatively low cytotoxicity.

\section{Discussion}

With the development of high sensitivity and high specificity probe technology in the field of biomedical research, the limitations of organic fluorescent dyes has become increasingly obvious. The application of QDs to molecular and cell biology, molecular imaging, and medical diagnostics has drawn wide attention.

QDs are special semiconductor nanocrystals with sizes ranging from 2 to $10 \mathrm{~nm}$ that contain hundreds to thousands of atoms of group II-VI or III-V elements [18]. Compared with traditional organic fluorescent dyes, the use of QDs as fluorescent biological probes has the following advantages. QDs with different emission colors can be excited simultaneously with a single light source. The fluorescent color of QDs changes with the diameter of the particle; this feature provides significant advantages for multiplex imaging of a single molecular target. Moreover, in contrast to organic fluorophores, QDs are highly resistant to chemical

\section{KARGER}


and metabolic degradation and have a higher photobleaching threshold. Treatment of cells with QDs for a certain period of time does not affect their normal physiological activity, e.g., growth, development, signal transduction, and migration. Therefore, in general, some QDs have good biocompatibility and can be used in biotechnology.

Previous studies have shown [19] that pancreatic cancer cells express high levels of $\alpha v \beta_{3}$ integrin receptors on their surface. Integrin $\alpha v \beta_{3}$ is a receptor for many extracellular matrix ligands, which expose the amino acid sequence Arg-Gly-Asp (RGD). Integrin $\alpha v \beta_{3}$ has been shown to be involved in tumor progression, growth, angiogenesis, and metastasis [20]. Therefore, we envisaged that by designing a polypeptide containing the RGD sequence, or peptide analogs, to inhibit $\alpha v \beta_{3}$ integrin, we could thus inhibit angiogenesis [21]. In this study, we found, using confocal laser scanning microscopy that the QD-RGD probe bound specifically to pancreatic cancer cells and mainly marked the surface of these cells. These observations provide some experimental basis for the application of QD-RGD probes in the early diagnosis and potential targeted therapy of pancreatic cancer.

In this study, we found that low concentrations of the QD-RGD probe ( $\leq 15 \mathrm{nmol} / \mathrm{L})$ can mark pancreatic cancer cells with high fluorescence intensity. QD probes can generate intense stable fluorescence even after long periods of excitation; therefore, QD-RGD probes have good light stability, imaging capabilities, and persistence, which are significant advantages over the traditional organic dyes used in biological imaging. This provides a powerful tool for long-term research and observation of the dynamic changes of tumor cells.

The toxicity of QDs is a major concern for their use as a bioimaging tool [22-24]. A large number of factors affect the toxicity of QDs, including their preparation, physical and chemical properties, concentration, target cell, incubation time, etc. Some reports have mentioned that the breakdown of QDs releases cadmium ions into the cellular environment and causes ill effects to the body $[25,26]$. In this study, we used water-soluble phase synthesized QDs grafted with EDC and NHS to produce the QD-RGD probe, which minimizes the toxicity of the QDs. Therefore, the QD-RGD probe used in this study has good biocompatibility and stability.

The MTT experiments suggest that low concentrations of the QD-RGD probe have relatively low cytotoxicity and good biocompatibility. As the concentration increased, the cell viability reduced significantly. When the QD-RGD probe concentration increases, as well as the extension of the incubation time, the number of QDs within phagocytic cells may also increase correspondingly. This causes difficulties in cell metabolism, thereby affecting the activity and metabolism of the cells.

In summary, we have introduced a simple and straightforward approach to produce a QD-RGD probe as an ideal target tumor biomarker, which has excellent optical properties and biocompatibility. It is a powerful tool for the early diagnosis and potential targeted therapy of pancreatic cancer. The application of fluorescent markers to biomolecular recognition is one of the current areas of focus in the life sciences. As a new type of fluorescent probe, QD-RGD probes will become one of the most promising fluorescent markers in the field of pancreatic cancer cell imaging and targeted in vivo imaging studies. These probes provide new methods and ideas for the early diagnosis and targeted therapy of pancreatic cancer, and also provide a new research tool to examine the incidence of pancreatic cancer, invasion, transfer mechanism, tumor diagnosis, treatment, and real-time monitoring. With the development of QD synthesis technology and surface functionalization, QDs will play an increasingly important role in tumor biomedical applications. However, there are certain problems and limitations, such as the toxicity of QDs that need to be addressed. Currently, there are only a few reports describing metabolism and toxicity problems of QDs in animals. In addition, no study has reported their application to humans. Future studies should be performed to improve the surface structure of QDs and their functionalization, which will make them more effective in combination with biological molecules.

\section{Disclosure Statement}

None.

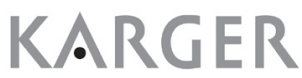




\section{Cellular Physiology Cell Physiol Biochem 2016;38:1121-1128 \begin{tabular}{ll|l} 
and BiOChemistry & $\begin{array}{l}\text { DOI: 10.1159/000443062 } \\
\text { Published online: March 11, } 2016\end{array}$ & $\begin{array}{l}\text { (c) 2016 The Author(s). Published by S. Karger AG, Basel } \\
\text { www.karger.com/cpb }\end{array}$
\end{tabular} \\ Li et al.: Quantum Dots as Novel Marker for Pancreatic Cancer Cells}

\section{References}

1 Baron TH, Kozarek RA: Preoperative biliary stents in pancreatic cancer--proceed with caution. N Engl J Med 2010;362:170-172.

2 Hruban RH, Maitra A, Kern SE, Goggins M: Precursors to pancreatic cancer. Gastroenterol Clin North Am 2007;36:831-849.

3 Montet X, Weissleder R, Josephson L: Imaging pancreatic cancer with a peptide-nanoparticle conjugate targeted to normal pancreas. Bioconjug Chem 2006;17:905-911.

4 Biju V, Mundayoor S, Omkumar RV, Anas A, Ishikawa M: Bioconjugated quantum dots for cancer research: Present status, prospects and remaining issues. Biotechnol Adv 2010;28:199-213.

5 Chan WC, Nie S: Quantum dot bioconjugates for ultrasensitive nonisotopic detection. Science 1998;281:2016-2018.

6 Dubertret B, Skourides P, Norris DJ, Noireaux V, Brivanlou AH, Libchaber A: In vivo imaging of quantum dots encapsulated in phospholipid micelles. Science 2002;298:1759-1762.

7 Konkar A, Lu S, Madhukar A, Hughes SM, Alivisatos AP: Semiconductor nanocrystal quantum dots on single crystal semiconductor substrates: High resolution transmission electron microscopy. Nano Lett 2005;5:969-973.

8 Yong KT, Sahoo Y, Swihart MT, Prasad PN: Growth of PdSe quantum rods and multipods seeded by noble metal nanoparticles. Adv Mater 2006;18:1978-1982.

9 Jamieson T, Bakhshi R, Petrova D, Pocock R, Imani M, Seifalian AM: Biological applications of quantum dots. Biomaterials 2007;28:4717-4732.

10 Yong KT, Roy I, Pudavar HE, Bergey EJ, Tramposch KM, Swihart MT, Prasad PN: Multiplex imaging of pancreatic cancer cells by using functionalized quantum rods. Adv Mater 2008;20:1412-1417.

11 Erogbogbo F, Yong KT, Roy I, Xu G, Prasad PN, Swihart MT: Biocompatible luminescent silicon quantum dots for imaging of cancer cells. ACS Nano 2008;2:873-878.

12 Smith AM, Duan H, Mohs AM, Nie S: Bioconjugated quantum dots for in vivo molecular and cellular imaging. Adv Drug Deliv Rev 2008;60:1226-1240.

13 Yong KT, Ding H, Roy I, Law WC, Bergey EJ, Maitra A, Prasad PN: Imaging pancreatic cancer using bioconjugated InP quantum dots. ACS Nano 2009;3:502-510.

14 Duan YJ, Liang HY, Jin WJ, Cui ZJ: Substance P conjugated to CdTe quantum dots triggers cytosolic calcium concentration oscillations and induces quantum dots internalization in the pancreatic carcinoma cell line AR4-2J. Anal Bioanal Chem 2011;400:2995-3003.

15 Reynolds AR, Hart IR, Watson AR, Welti JC, Silva RG, Robinson SD, Da VG, Gourlaouen M, Salih M, Jones MC, Jones DT, Saunders G, Kostourou V, Perron-Sierra F, Norman JC, Tucker GC, Hodivala-Dilke KM: Stimulation of tumor growth and angiogenesis by low concentrations of RGD-mimetic integrin inhibitors. Nat Med 2009;15:392-400.

16 Ji S, Xu J, Zhang B, Yao W, Xu W, Wu W, Xu Y, Wang H, Ni Q, Hou H, Yu X: RGD-conjugated albumin nanoparticles as a novel delivery vehicle in pancreatic cancer therapy. Cancer Biol Ther 2012;13:206-215.

17 Wang Y, Yan XP: Fabrication of vascular endothelial growth factor antibody bioconjugated ultrasmall near-infrared fluorescent Ag2S quantum dots for targeted cancer imaging in vivo. Chem Commun (Camb) 2013;49:3324-3326.

18 Yong KT: Biophotonics and biotechnology in pancreatic cancer: Cyclic RGD-peptide-conjugated type II quantum dots for in vivo imaging. Pancreatology 2010;10:553-564.

19 Hosotani R, Kawaguchi M, Masui T, Koshiba T, Ida J, Fujimoto K, Wada M, Doi R, Imamura M: Expression of integrin alphaVbeta3 in pancreatic carcinoma: Relation to MMP-2 activation and lymph node metastasis. Pancreas 2002;25:e30-e35.

20 von Wallbrunn A, Holtke C, Zuhlsdorf M, Heindel W, Schafers M, Bremer C: In vivo imaging of integrin alpha v beta 3 expression using fluorescence-mediated tomography. Eur J Nucl Med Mol Imaging 2007;34:745754.

21 Mulder WJ, Castermans K, van Beijnum JR, Oude EM, Chin PT, Fayad ZA, Lowik CW, Kaijzel EL, Que I, Storm G, Strijkers GJ, Griffioen AW, Nicolay K: Molecular imaging of tumor angiogenesis using alphavbeta3integrin targeted multimodal quantum dots. Angiogenesis 2009;12:17-24.

22 Kennel SJ, Woodward JD, Rondinone AJ, Wall J, Huang Y, Mirzadeh S: The fate of MAb-targeted Cd(125m) Te/ZnS nanoparticles in vivo. Nucl Med Biol 2008;35:501-514. 
Cellular Physiology Cell Physiol Biochem 2016;38:1121-1128

\begin{tabular}{l|l|l}
\hline and Biochemistry 10.1159/000443062 & $\begin{array}{l}\text { ○ 2016 The Author(s). Published by S. Karger AG, Basel } \\
\text { www.karger.com/cpb }\end{array}$ \\
\hline
\end{tabular}

Li et al.: Quantum Dots as Novel Marker for Pancreatic Cancer Cells

23 Maysinger D, Lovric J, Eisenberg A, Savic R: Fate of micelles and quantum dots in cells. Eur J Pharm Biopharm 2007;65:270-281.

24 Su Y, He Y, Lu H, Sai L, Li Q Li W, Wang L, Shen P, Huang Q, Fan C: The cytotoxicity of cadmium based, aqueous phase - synthesized, quantum dots and its modulation by surface coating. Biomaterials 2009;30:19-25.

25 Chang E, Thekkek N, Yu WW, Colvin VL, Drezek R: Evaluation of quantum dot cytotoxicity based on intracellular uptake. Small 2006;2:1412-1417.

26 Chen Z, Chen H, Meng H, Xing G, Gao X, Sun B, Shi X, Yuan H, Zhang C, Liu R, Zhao F, Zhao Y, Fang X: Bio-distribution and metabolic paths of silica coated CdSeS quantum dots. Toxicol Appl Pharmacol 2008;230:364-371. 